\title{
Perancangan Alat Bantu Swing Otomatis Untuk Mengurangi Kegagalan Produk Pada Industri Bahan Bangunan
}

\author{
Pawenary'; Meyhart Sitorus $^{2}$; Hastuti Azis ${ }^{3}$ \\ 1, 2, 3 Sekolah Tinggi Teknik PLN \\ 1 pawenary@sttpln.ac.id
}

\begin{abstract}
Product failure is a condition of a product that is dissimiliar with the intended purpose or goal. Product failure control is a system of verification and maintenance of desired quality level of product or process. The purpose of this study is to find out the right method to use in designing and installing assistive devices to reduce the product failure. Furthermore, this study provides an overview of the improvement of automatic swing aid, so that the products that are wasted can be utilized more optimally, so the company can increase its profits. From the literature study, it was found that the design and redesign to improve this tool used two methods, namely: Focus Group Discussion and Quality Function Development. Analyzing automatic swing aid give result that it can be used as an alternative to help companies reduce production costs and increase company profits. The use of a proximity sensor that is capable to cetect physical contact can be used to facilitate the design of the automatic swing aid. Using pneumatic valve solenoid makes automatic swing aid works better.
\end{abstract}

Keywords: Redesign, automatic swing aid, proximity sensor, solenoid valve pneumatic

\begin{abstract}
ABSTRAK
Kegagalan produk adalah kondisi suatu produk yang tidak sesuai dengan maksud atau tujuan yang diinginkan. Pengendalian kegagalan produk merupakan suatu sistem verifikasi dan penjagaan/ perawatan dari suatu tingkatan kualitas produk atau proses yang dikehendaki. Tujuan dari penelitian ini adalah untuk mengetahui metode yang tepat untuk digunakan dalam perancangan dan pemasangan alat bantu agar mengurangi kegagalan produk. Selain itu penelitian ini memberikan gambaran mengenai perbaikan alat bantu swing otomatis agar produk yang terbuang dapat dimanfaatkan lebih maksimal, sehingga perusahaan dapat meningkatkan keuntungannya. Dari studi literatur didapatkan perancangan dan redesign untuk perbaikan alat bantu ini baik menggunakan dua metode, yaitu : Focus Group Discussion dan Quality Function Development. Selanjutnya alat bantu swing otomatis dianalisis dan hasilnya ia dapat dijadikan sebagai salah satu alternatif yang bisa membantu perusahaan mengurangi biaya produksi dan meningkatkan keuntungan perusahaan. Penggunaan sensor proksimitas yang mampu mendeteksi kontak fisik dapat digunakan untuk memudahkan perancangan swing otomatis tersebut. Dengan digunakannya solenoid valve pneumatic, menjadikan alat tersebut bekerja dengan lebih baik.
\end{abstract}

Kata kunci: Redesign, swing otomatis, sensor proksimitas, solenoid valve pneumatic 


\section{PENDAHULUAN}

Kegagalan produk adalah kondisi dari suatu produk yang tidak sesuai dengan maksud atau tujuan yang diinginkan. Pengendalian kegagalan produk ini adalah suatu sistem verifikasi dan penjagaan/perawatan dari suatu tingkatan kualitas produk atau proses yang dikehendaki, dengan cara perencanaan yang saksama, pemakaian peralatan yang sesuai, inspeksi yang terus menerus, serta tindakan korektif dan inovatif apabila diperlukan. Pengelolaan produk yang gagal juga bisa dilakukan dengan me-recycle ulang menjadi produk sejenis ataupun mengolahnya menjadi jenis produk lain yang dapat dimanfaatkan berdasarkan berbagai macam tipe produk yang gagal tersebut.

Kegagalan produk apabila tidak diproses ulang akan menjadi limbah. PT Bakrie Building Industries saat ini merupakan salah satu produsen bahan bangunan berbasis fibre cement terbesar di Indonesia. Dengan kapasitas produksi 200.000 ton per tahun, produkproduk bahan bangunan fibre cement, PT BBI saat ini menguasai sedikitnya $25 \%$ pangsa pasar nasional. Produk lembar kalsium siliket yang dihasilkan PT Bakrie Industries telah banyak digunakan oleh property jenis perumahan.

Tujuan penelitian ini adalah memberikan gambaran mengenai perbaikan alat bantu swing otomatis agar produk yang terbuang dapat dimanfaatkan lebih maksimal, sehingga perusahaan dapat meningkatkan keuntungannya. Tujuan lainnya adalah untuk mengetahui metode yang tepat untuk digunakan dalam perancangan dan pemasangan alat bantu untuk mengurangi kegagalan produk. Manfaat yang diharapkan dari penelitian ini adalah memberikan gambaran tentang perancangan alat bantu bagi perusahaan agar bisa lebih memanfaatkan produk gagal sehingga dapat mengurangi biaya produksi dan meningkatkan keuntungan.

Permasalahan dalam penelitian ini adalah bagaimana metode yang seharusnya dilakukan untuk mengurangi kegagalan produk dengan memaksimalkan hasil produk yang terbuang pada saat pergantian lorry pada sheet machine I melalui redesign atau perancangan ulang alat bantu yang tepat pada produksi fibre cement agar produk yang terbuang dapat diolah kembali sehingga dapat meningkatkan keuntungan perusahaan. Penelitian ini dilakukan bekerjasama dengan PT Bakrie Building Industries, di mana PT BBI merupakan perusahaan yang bergerak di bidang industri fibre cement. Penelitian lebih difokuskan pada divisi produksi khususnya untuk sheet machine I, di mana penelitian ini membahas tentang penanganan kegagalan produk, penghematan cost yang didapat selama 1 tahun yang memberikan keuntungan/profit bagi perusahaan. Penelitian juga membahas redesign/perancangan ulang alat bantu yang dibuat, sistem otomatis kerja alat bantu, serta biaya yang timbul dari perancangan alat bantu tersebut.

Produk dapat diartikan sebagai keluaran (output) yang diperoleh dari sebuah proses produksi (transformasi) dan merupakan pertambahan nilai dari bahan baku (material input) dan merupakan komoditi yang dijual perusahaan kepada konsumen [1]. W. Edwards Deming (1982:176) menyatakan, bahwa kualitas adalah kesesuaian dengan kebutuhan pasar [2]. Kualitas yang baik menurut produsen adalah apabila produk yang dihasilkan oleh perusahaan telah sesuai dengan spesifikasi yang telah ditentukan oleh perusahaan. Namun demikian perusahaan dalam menentukan spesifikasi produk juga harus memperhatikan keinginan dari konsumen, sebab tanpa memperhatikan produk yang dihasilkan oleh perusahaan tidak akan dapat bersaing dengan perusahaan lain yang lebih memperhatikan kebutuhan konsumen. Secara umum, sebagaimana ditulis oleh M. N. Nasution (2005: 4-5) dan Douglas C. Montgomery (2001:2) dalam bukunya, 
mengidentifikasikan delapan dimensi kualitas yang dapat digunakan untuk menganalisis karakteristik kualitas barang, yaitu sebagai berikut [3] :

1. Performa (performance)

2. Keistimewaan (features)

3. Keandalan (reliability)

4. Konformasi (conformance)
5. Daya tahan (durability)

6. Kemampuan Pelayanan (serviceability)

7. Estetika (esthetics)

8. Kualitas yang dipersepsikan (perceived quality)

Menurut Sofjan Assauri (1998:25), pengendalian dan pengawasan adalah kegiatan yang dilakukan untuk menjamin agar kegiatan produksi dan operasi yang dilaksanakan sesuai dengan apa yang direncanakan dan apabila terjadi penyimpangan, maka penyimpangan tersebut dapat dikoreksi sehingga apa yang diharapkan dapat tercapai [4]. Sedangkan menurut Vincent Gasperz (2005:480), pengendalian adalah control can mean an evaluation to indicate needed corrective responses, the act guilding, or the state of process in which the variability is attribute to a constant system of chance couses [5].

Tujuan utama pengendalian kualitas adalah untuk mendapatkan jaminan bahwa kualitas produk atau jasa yang dihasilkan sesuai dengan standar kualitas yang telah ditetapkan dengan mengeluarkan biaya yang ekonomis atau serendah mungkin. Tujuan lain dari pengendalian kualitas menurut Sofjan Assauri (1998:210) adalah [4]:

1. Agar barang hasil produksi dapat mencapai standar kualitas yang telah ditetapkan.

2. Mengusahakan agar biaya inspeksi dapat menjadi sekecil mungkin.

3. Mengusahakan agar biaya desain dari produk dan proses dengan menggunakan kualitas produksi tertentu dapat menjadi sekecil mungkin.

4. Mengusahakan agar biaya produksi dapat menjadi serendah mungkin.

Selanjutnya mengenai Focus Group Discussion (FGD). FGD adalah diskusi dengan peserta terbatas yang berasal dari satu kelompok tertentu dan dengan topik bahasan diskusi tertentu pula. Metode $F G D$ ini adalah untuk menambah dan memperdalam informasi, membangun kesepakatan/komitmen, mengkalrifikasi informasi yang kurang pada basis data dan juga bisa dipakai untuk memperoleh opini-opini yang berbeda mengenai satu permasalahan tertentu. Tahapan pelaksanaan FGD dibagi dalam tiga fase kritis. Dan fase ketiga adalah memodifikasi desain produk atau proses terbaru dan pengembangan proses pengendalian. Secara ringkas, tahapan itu digambarkan pada Tabel 1 berikut ini.

Tabel 1. Tahapan Pelaksanaan Focus Group Discussion (FGD)

\begin{tabular}{|c|l|l|}
\hline Fase & \multicolumn{1}{|c|}{ Pertanyaan } & \multicolumn{1}{c|}{ Hasil } \\
\hline Identifikasi & - Apa yang salah & $\begin{array}{l}\text { - Deskripsi kegagalan } \\
\text { - Penyebab Kegagalan }\end{array}$ \\
\hline \multirow{2}{*}{ Analisis } & $\begin{array}{l}\text { - Seperti apa kegagalannya? } \\
\text { - Apa konsekuensinya? }\end{array}$ & $\begin{array}{l}\text { - Jumlah Nilai } \\
\text { - Tingkat Pengaruh }\end{array}$ \\
\hline \multirow{3}{*}{ Tindakan } & - Apah yang bisa dilakukan & - Solusi desain \\
& - bagaimana cara mengeliminasi & - Rencana pengujian \\
& $\begin{array}{l}\text { - bagaimana cara mereduksi } \\
\text { keparahan? }\end{array}$ & $\begin{array}{l}\text { - Perubahan proses } \\
\text { produksi }\end{array}$ \\
& - Pencegahan eror \\
\hline
\end{tabular}


Dalam konteks pemenuhan kebutuhan dan keinginan pelanggan maka salah satu konsep yang dikenal adalah Quality Function Deployment atau biasa disingkat dengan QFD. Quality Function Deployment (QFD) adalah metode perencanaan dan pengembangan produk/jasa secara terstruktur yang memungkinkan tim. pengembang mendefinisikan secara jelas kebutuhan dan harapan tersebut dan mengevaluasi kemampuan produk atau jasa secara sistematik untuk memenuhi kebutuhan dan harapan tersebut, (Wahyu, 2003: 184) [6].

Untuk memahami mengenai QFD dilakukan studi literatur dari beberapa penulis mengenai QFD, yaitu Cohen[7], Murat Gunduz[8], Hartanto [9] dan Kay C. Tan[10]. Penerapan QFD dapat mengurangi waktu desain sebesar $40 \%$ dan biaya desain sebesar $60 \%$ secara bersamaan dengan kualitas desain yang tetap dipertahankan dan ditingkatkannya. Manfaat yang dapat diperoleh dari QFD bagi perusahaan yang berusaha meningkatkan daya saingnya melalui perbaikan kualitas dan produktivitasnya secara berkesinambungan. Manfaat tersebut antara lain adalah fokus pada pelanggan, efisiensi waktu, orientasi pada kerjasama tim dan orientasi pada dokumentasi (Nasution, Arman Hakim 2006) [11]. Dengan menggunakan QFD, perusahaan dapat mengurangi jumlah perubahan desain, menurunkan biaya startup, siklus desain yang lebih pendek, mengurangi keluhan pelanggan, meningkatkan komunikasi internal dan meningkatkan penjualan (Surjandari, Isti., 2010)[12] .

Desain suatu produk baru harus memahami konsep dalam pengembangan suatu produk. Dalam pandangan perusahaan yang berorientasi pada keuntungan (profit oriented enterprise), kesuksesan perancangan dan pengembangan produk (Widodo, 2006;) [13] disesuaikan oleh:

1. Kualitas produk

2. Biaya produk. Produk harus dapat diproduksi dengan biaya yang murah.

3. Waktu pengembangan produk

4. Kapabilitas Pengembangan Produk

Tiga fungsi yang paling penting bagi proses pengembangan produk (Ulrich dan Epingger, 2001) [14] yaitu:

1. Pemasaran, menjembatani interaksi antara perusahaan dengan pelanggan,

2. Perancangan, mendefinisikan bentuk fisik produk agar dapat memenuhi kebutuhan pelanggan.

3. Manufaktur,bertanggung jawab untuk merancang dan mengoperasikan sistem produksi pada proses produksi produk. Menurut Yamit (1996) [15] pengembangan produk merupakan keharusan bagi perusahaan untuk dapat mempertahankan kelangsungan hidupnya.

Selain uraian di atas, perancangan dan pengembangan suatu produk juga terdapat aktifitas produksi lain yang akan melibatkan penanganan pengendalian kualitas, mulai dari pengawasan bahan baku, bahan produksi, sampai barang jadi. Untuk memantapkan mengenai perancangan dan pengembangan produk dilakukan studi literatur dari beberapa penulis, Heizer [16], Richard B. Chase[17], Schroeder [18], dan Sutalaksana [19].

Tahap pengembangan adalah melakukan penelitian terhadap kruk yang sudah ada atau beredar, untuk dikembangkan lebih jauh agar memiliki tingkat kegunaan yang lebih tinggi dan lebih disukai pemakai. Dan dipakai sebagai dasar untuk meningkatkan hasil yang diperoleh. Penelitian dan pengembangan produk diharapkan dapat menghasilkan produk 
baru, adapun yang dimaksud produk baru adalah produk yang mempunyai salah satu atau lebih dari kriteria-kriteria berikut ini (Assauri, 1985;26) [4].

1. Terdapat perubahan kecil dari produk yang telah diproduksi.

2. Terdapat perubahan total dari produk yang telah diproduksi, missal perubahan sistem atau sub sistem produk.

3. Produk yang sudah diproduksi oleh perusahaan lain tetapi belum pernah diproduksi oleh perusahaan yang bersangkutan.

4. Produk yang belum pernah diproduksi oleh perusahaan dalam negeri, walaupun produk tersebut sudah ada dan sudah di pasarkan di Negara lain.

Desain produk merupakan skema di mana elemen-elemen fungsional dan produk disusun menjadi beberapa kumpulan komponen yang berbentuk fisik. Pendesainan ditetapkan selama fase pengembangan konsep dan perancangan tingkatan sistem (Ulrich dan Eppinger, 2001; 171) [14]. Metode untuk menetapkan desain produk terdiri beberapa tahap, yaitu:

1. Membuat skema produk

2. Mengelompokan elemen-elemen yang terdapat pada skema.

3. Membuat rancangan geometris yang masih kasar.

Selanjutnya mengenai alat bantu. Sensor proksimitas adalah sensor yang mampu mendeteksi kehadiran objek di sekitar tanpa melalui kontak fisik. Sensor proksimitas memancarkan medan elektromagnetik atau sinar radiasi elektromagnetik (inframerah misalnya), dan mencari perubahan dalam medan atau sinyal yang kembali. Selain sensor proximitas digunakan juga starter magnit (magnetic contractor). Sebagai pelindung rangkaian motor digunakan sekering dan overload relay. Starter magnit adalah saklar magnit yang dilengkapi overload.

Solenoid valve pneumatic adalah katup yang digerakan oleh energi listrik, mempunyai kumparan sebagai penggeraknya yang berfungsi untuk menggerakan plunger yang dapat digerakan oleh arus AC maupun DC.
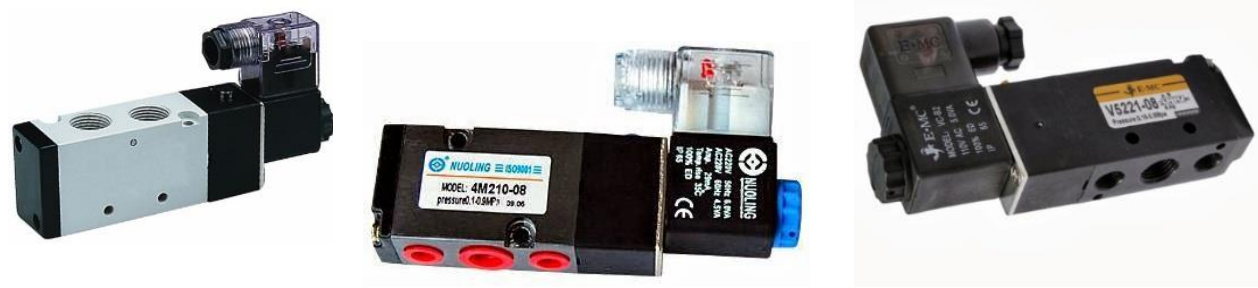

Gambar 1. Solenoid Valve

Prinsip kerja dari solenoid valve/katup (valve) solenoida yaitu katup listrik yang mempunyai koil sebagai penggeraknya di mana ketika koil mendapat supply tegangan, maka koil tersebut akan berubah menjadi medan magnet. Sehingga menggerakan plunger pada bagian dalamnya ketika plunger berpindah posisi maka pada lubang keluaran dari solenoid valve pneumatic akan keluar udara bertekanan yang berasal dari supply (service unit).

Di bawah ini dapat dilihat cara kerja plunger solenoid valve pneumatic dalam menyalurkan udara bertekanan kedalam tabung pneumatik (silinder pneumatik kerja tunggal). 


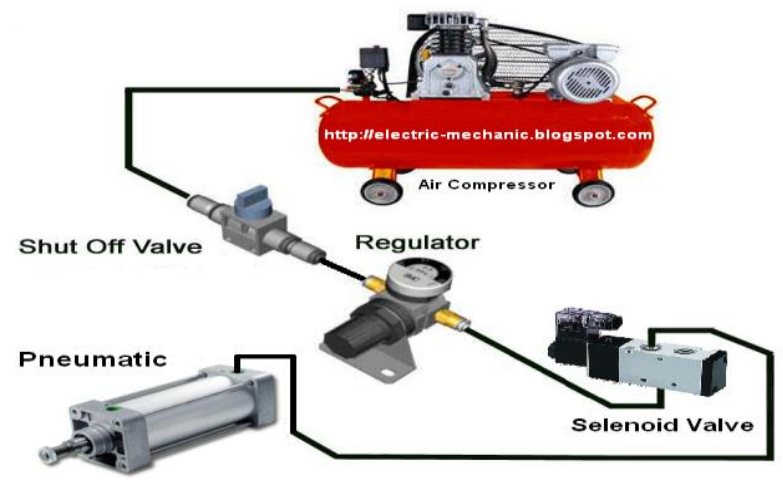

Gambar 2. Prinsip Kerja Solenoid Valve

Kompressor diaktifkan dengan cara menghidupkan penggerak mula umumnya motor listrik. Udara akan disedot oleh kompresor kemudian ditekan dalam tangki udara hingga mencapai tekanan beberapa bar. Untuk menyalurkan udara bertekanan ke seluruh sistem (sirkuit pneumatik) diperlukan unit pelayanan atau service unit yang terdiri dari penyaring (filter), katup kran (shut off valve) dan pengatur tekanan (regulator).

Service unit ini diperlukan karena udara bertekanan yang diperlukan di dalam sirkuit pneumatik harus benar-benar bersih. Selanjutnya udara bertekanan disalurkan dengan bekerjanya solenoid valve pneumatic ketika mendapat tegangan input pada kumparan dan menarik plunger sehingga udara bertekanan keluar dari outlet port melalui selang elastis menuju katup pneumatik (katup pengarah/inlet port pneumatic). Udara bertekanan yang masuk akan mengisi tabung pneumatik (silinder pneumatik kerja tunggal) dan membuat piston bergerak maju dan udara bertekanan tersebut terus mendorong piston dan akan berhenti di lubang outlet port pneumatic atau batas dorong piston.

\section{METODE/PERANCANGAN PENELITIAN}

Perancangan alat bantu swing otomatis dilakukan dengan metode robotik.Fokus utama adalah seberapa mampu alat bantu swing tersebut mengurangi kegagalan produk yang terjadi di perusahan, baik dari teknis maupun finansial sehingga bisa diimplementasikan penggunaannya secara nyata untuk membantu produksi perusahaan industri. Data penelitan bersumber dari catatan serta data produksi perusahaan PT Bakrie Building Industries. Data tersebut berupa data produksi, data kegagalan produksi, data keuntungan serta kerugian akibat kegagalan produksi, serta data mesin yang digunakan.

Pengolahan data menggunakan metode kuantitatif, yaitu metode yang bersifat sistematis dan menggunakan model-model matematis. Dalam penelitian ini, kita akan mengetahui perbedaan antara mesin lama dan baru. Selain itu, data juga di dapat berdasarkan metode quality function deployment, atau kuesioner yang terdiri dari enam pertanyaan untuk produk alat bantu swing akan diuji validitas (keabsahan) dan reliabilitas (keandalan) dari alat ukur yang digunakan dalam penelitian ini. 


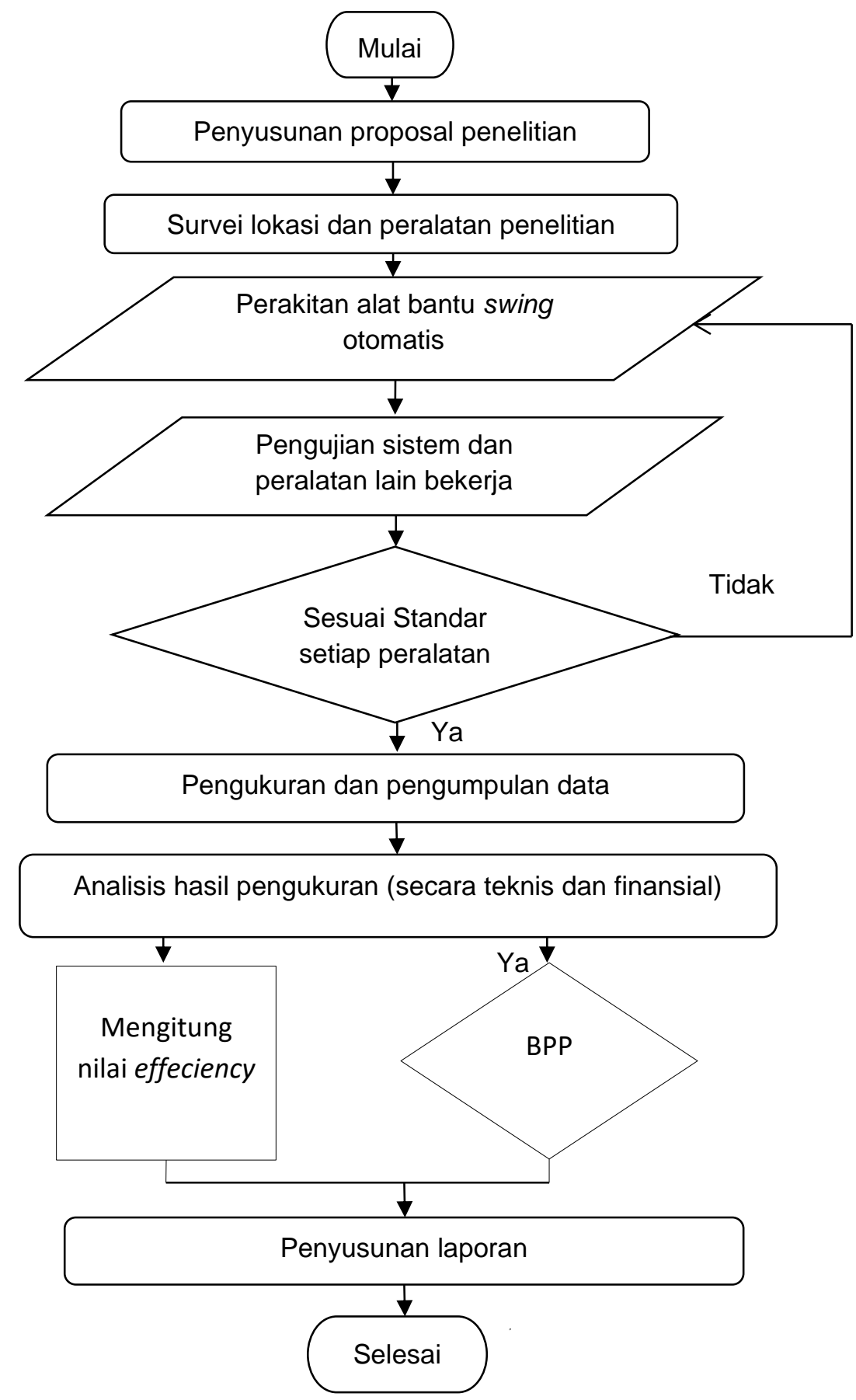

Gambar 3. Teknik Analisis Penelitian

\section{HASIL DAN PEMBAHASAN}

\subsection{Data Hasil Setelah Pemasangan Alat Bantu}

Setelah pemasangan swing arm dengan menggunakan air cylender \& regulator velve, secara signifikan scrap return berkurang kembali. Data reject setelah pemasangan Air Cylinder \& Regulator Valve ditunjukkan oleh Tabel 2 berikut ini. 
Tabel 2. Data Reject Setelah Pemasangan Air Cylinder \& Regulator Valve

\begin{tabular}{|c|c|c|c|c|c|c|}
\hline \multirow{2}{*}{ NO } & \multirow{3}{*}{ Bulan } & \multicolumn{5}{|c|}{ Jenis Reject ( Lembar ) } \\
\cline { 3 - 7 } & & Scrap & Side & Lap & Too & Test \\
\cline { 3 - 7 } & Return & Flat & Fault & Thin & Lab \\
\hline 1 & Apr'11 & 6.724 & 642 & 683 & 59 & 67 \\
\hline 2 & Mei'11 & 6.545 & 787 & 564 & 53 & 64 \\
\hline \multicolumn{2}{|c}{ Total } & $\mathbf{1 3 . 2 6 9}$ & $\mathbf{1 . 4 2 9}$ & $\mathbf{1 . 2 4 7}$ & $\mathbf{1 1 2}$ & $\mathbf{1 3 1}$ \\
\hline
\end{tabular}

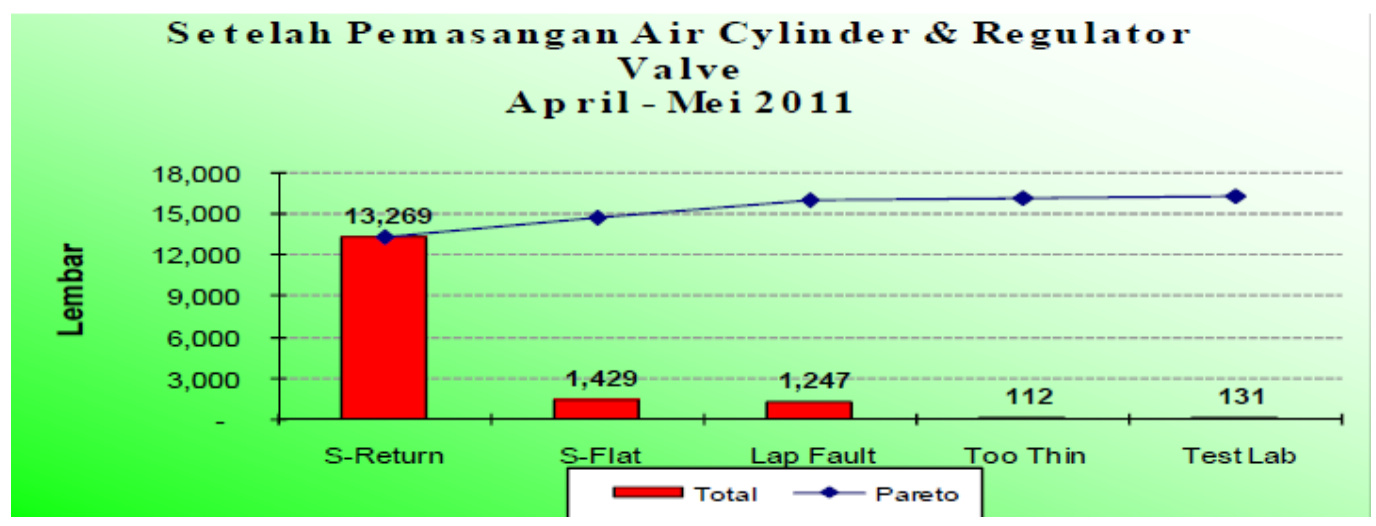

Gambar 4. Diagram Pareto Reject Setelah Pemasangan Air Cylinder \& Regulator Valve

Penurunan reject dari scrap return cukup signifikan dari 66.540 lembar selama enam bulan sebelum pemasangan air cylender \& regulator velve menjadi 13.269 lembar selama dua bulan setelah pemasangan Swing Arm dengan menggunakan air cylender \& regulator velve. Rata-rata scarp return ketika menggunakan swing arm adalah $66.540: 6=11.090$ lembar/bulan, sedangkan rata-rata scarp return yang telah menggunakan swing arm dan air cylender \& regulator velve adalah 13.269:2 $=6.635$. Maka dapat dianalisa bahwa pemakaian swing arm pada pergantian lorry truck, dapat mengurangi scrap return hingga 4.455 lembar satu bulan. Atau dapat dikatakan rata-rata scrap return dalam tahunan mencapai 4.455 * 12 bulan $=53.460$. Didapatkan jumlah scrap return untuk dalam satu hari adalah. Jumlah Scrap Return $=4.455$ lembar : 25 hari $=179$ lembar/hari.

Dalam satu hari ada 3 shift, sehingga didapatkan jumlah scrap return untuk satu stacker selama satu hari. Jumlah Scrap Return $=179$ lembar $: 3$ shift $=60$ lembar $/$ shift. Jumlah jam kerja dalam satu shift 8 jam, apabila mesin di tergetkan beroperasi 8 jam maka. Jumlah Scrap Return = 60 lembar $: 8$ jam = 8 lembar/jam. Sehingga kalau di bandingkan dengan sebelum pemakaian swing arm yang 25 lembar per jam, maka di dapatkan pengurangan sebanyak 17 lembar per jam, setelah menggunakan swing dilengkapi dengan air cylinder \& regulator valve.

\subsection{Pembahasan}

Rework yang terjadi pada penelitian di PT Bakrie Building Industries adalah proses yang berulang dikarenakan adanya proses pergantian lorry Truck. Penurunan reject dari scrap return cukup signifikan dari 170.389 lembar selama enam bulan sebelum pemasangan menjadi 66.540 lembar selama enam bulan setelah pemasangan Swing Arm. Maka dapat dianalisa bahwa pemakaian Swing Arm pada Pergantian lorry Truck, dapat 
mengurangi scrap return hingga 103.849 selama 6 bulan. Untuk rata-rata perbulan scrap return dapat berkurang sebanyak 17.309 per bulan.

Focus group discussion dalam penelitian ini dilakukan dalam 2 (dua) tahap. Tahap pertama dilakukan oleh bagian produksi dan maintenance untuk mengatahui kebutuhan bagian tersebut terhadap kinerja alat bantu yang sudah ada (swing) dengan cara mengidentifikasi kemudahaan pendeteksian kerusakan yang sering terjadi pada alat bantu, peluang kerusakan pada alat bantu dan pengaruh yang terjadi pada proses produksi. Tahap kedua adalah FGD untuk menentukan parameter teknik yang dibutuhkan oleh bagian produksi dan maintenance sehingga nantinya dapat melakukan perancangan ulang dan meningkatkan kinerja alat bantu.

Hasil dari quality function deployment, berdasarkan prioritas tertinggi adalah meningkatkan phenomatic speed dengan menambah tekanan angin pada alat bantu swing. Sehingga tidak terjadi lagi keterlambatan swing pada proses produksi untuk product lembaran bahan bangunan. Dan jumlah product terbuang pada saat produksi juga semakin berkurang. Alat bantu swing ini terdiri dari lima bagian, yaitu Lengan (arm), Pemegang (bracket), Poros Pengunci (pin), Air Cylinder, dan Regulator Valve.

Lengan, pemegang dan poros pengunci adalah bagian inti dari alat bantu swing dan Air Cylinder dan Regulator Valve adalah alat yang ditambahkan untuk meningkatkan phenomatic speed sehingga jumlah product terbuang semakin berkurang. Proses instalasi untuk alat bantu swing terdiri dari lima tahapan, dimana tahapan ini memerlukan ketelitian dan keakuratan dalam menginstalnya, sehingga tidak terjadi gangguan pada kinerja komponen-komponen lain di area stacker.

Perusahaan seringkali dihadapkan pada situasi pengambilan keputusan mengenai perubahan. Salah satu metode yang umum digunakan adalah analisa cost \& benefit. Analisa cost \& benefit adalah teknik sederhana yang banyak digunakan untuk mengambil keputusan mengenai perubahan. Analisa cost dan benefit memungkinkan perusahaan untuk mencari tahu apakah sebuah keputusan mampu memberikan tambahan nilai. Analisa cost \& benefit dilakukan dengan membandingkan biaya dan benefit financial dari suatu keputusan.

\section{KESIMPULAN DAN SARAN}

Kesimpulan yang didapatkan dari hasil identifikasi dengan Focus Group Discussion (FGD) yaitu perlu dilakukan perbaikan terhadap alat bantu swing yang sudah terpasang, yaitu meningkatkan pneumatic speed dengan menambah tekanan angin. Untuk meningkatkan pneumatic speed tersebut, perlu dilakukan pemasangan air cylinder dan regulator valve. Dengan perancangan ulang swing tersebut, perusahaan dapat melakukan penghematan atau mendapat keuntungan.

Setelah dilakukan perancangan ulang untuk alat bantu swing dengan memasang air cylinder dan regulator valve masih banyak faktor lain yang menyebabkan sejumlah produk reject. Untuk itu, saran pada penelitian yang berikutnya diperlukan analisis faktor-faktor penyebab lainnya, dengan lebih mendalam sehingga dapat meminimalkan jumlah reject. Penelitian ini juga dapat menggunakan metode House of Quality sampai level 3 untuk dapat mengetahui quality procedures yang nantinya dapat dipergunakan sebagai solusi panduan pelaksanaan dalam operasional pada perusahaan. 


\section{UCAPAN TERIMAKASIH}

Penulis mengucapkan terima kasih kepada PT Bakrie Building Industries yang telah bersedia bekerja sama untuk pembelajaran dalam memperbaiki sistem yang ada pada perusahaan tersebut.

\section{DAFTAR PUSTAKA}

[1] I. D. Widodo, "Perencanaan dan Pengembangan Produk," Ull-Press: Yogyakarta, 2003.

[2] W. E. Deming, Quality, Productivity, and Competitive Position. Massachusetts Institute of Technology, Center for Advanced Engineering Study, 1982.

[3] M. N. Nasution, Manajemen mutu terpadu edisi kedua, 2nd ed. Ghalia Indonesia, 2005.

[4] S. Assauri, "Manajemen operasi dan produksi," Jakarta LP FE UI, p. 210, 1998.

[5] V. Gasperz, Total Quality Management. Jakarta: PT. Gramedia Pustaka Utama, 2005.

[6] D. W. ARIANI, Manajemen kualitas.-- ed.1. Universitas Atma Jaya, 1999.

[7] L. Cohen, Quality Function Deployment: How to Make QFD Work for You, 1 edition. Reading, Mass: Prentice Hall, 1995.

[8] M. Gunduz and B. Simsek, "A strategic safety management framework through balanced scorecard and quality function deployment," Can. J. Civ. Eng., vol. 34, no. 5, pp. 622-630, May 2007.

[9] S. HARTANTO, "ANALISA KUALITAS PELAYANAN PERPUSTAKAAN PERGURUAN TINGGI DENGAN METODE QUALITY FUNCTION DEPLOYMENT (QFD) (Studi Kasus: Perpustakaan Pusat UMS )," Universitas Muhammadiyah Surakarta, 2008.

[10] K. C. Tan and T. A. Pawitra, Integrating SERVQUAL and Kano's model into QFD for service excellence development, vol. 11. 2001.

[11] A. H. Nasution, "Manajemen industri," Yogyakarta Penerbit Andi, 2006.

[12] I. Surjandari, "Conjoint Analysis: Konsep dan Aplikasi," Penerbit Univ. Trisakti Undang. RI, no. 7, 2010.

[13] Imam Djati Widodo, Perancanaan dan Pengembangan Produk. Yogyakarta: UII Press, 2006.

[14] P. De Klein, Perancangan dan pengembangan produk: Karl T. Ulrich, Steven D. Eppinger; terj. Nora Azmi, Iveline Anne Marie. Salemba Teknika, 2001.

[15] Y. Zulian, "Manajemen Produksi dan Operasi," Ed. Kedua, Ekonisia, Yogyakarta, 2003.

[16] J. Heizer and B. Render, OPERATIONS MANAGEMENT (Manajemen Operasi), 7th ed. Jakarta: Salemba Empat, 2005.

[17] R. B. Chase, F. R. Jacobs, and N. J. Aquilano, Operations Management for Competitive Advantage 11th edition, 11th edition. McGraw-Hill/Irwin, 2006.

[18] R. G. Schroeder, Manajemen Operasi, 3rd ed. Jakarta: Penerbit Erlangga, 2007.

[19] I. Z. Sutalaksana, Teknik Tata Cara Kerja. Bandung: Institut Teknologi Bandung Press, 1979. 